\title{
Analysis of active islanding detection techniques for grid- connected inverters systems
}

\author{
Naima Ikken, Nour-Eddine Tariba, Abdelhadi Bouknadel, Ahmed Haddou, Hafsa El Omari, \\ Hamid El Omari \\ Department of the Physics and Engineering Science, Faculty of Science and Technology, Hassan I University, Settat, Morocco
}

\begin{abstract}
Article Info
Article history:

Received Feb 21, 2021

Revised Nov 27, 2021

Accepted Dec 23, 2022

\section{Keywords:}

AFD

Islanding detection

PSIM

SMS

ABSTRACT

An island is a section of the electrical grid that contains producing assets and loads that are separated from the main grid and powered by these generators, such as solar systems, with voltage and frequency maintained at nominal levels. It's worth noting that the concept of islanding is linked to time. When the inverter detects an isolated grid activity for a particular period of time, the inverter is compelled to decouple from the general grid, according to the criteria that dictate the working principle of a photovoltaic (PV) systemThis paper presents research and comparisons of the main islanding detection techniques for single-phase systems based on various structures, as well as a comparison of the improvement of the traditional islanding detection method using three different methods (active frequency drift (AFD), slip mode phase shift (SMS) and Sandia frequency shift (SFS)). Under normal and abnormal operating conditions, a comparison of these three examined improvements was made. Additionally, physical security information management (PSIM) software simulation results are generated to test the performance and effectiveness of the effective technique plan.
\end{abstract}

This is an open access article under the CC BY-SA license.

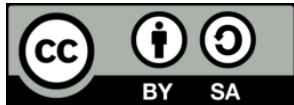

\section{Corresponding Author:}

Naima Ikken

Department of the Physics and Engineering Science, Faculty of Science and Technology

Hassan I University

FSTS, Km7, Road Casablanca, Settat, Morocco

Email: naima.ikken@gmail.com

\section{INTRODUCTION}

An island with these loads is formed by a decentralized generator that is separated from the main power grid but continues to supply the loads. This is referred to as islanding. This can be deliberate or unintentional. Indeed, the disconnecting of the electrical network during a repair operation can result in the islanding of generators. The island is recognized and can be switched off by intervening individuals because the network loss is voluntary.

The inadvertent islanding, which was caused by a power outage, is of higher interest. It does, in fact, pose a number of risks, including the possibility of electrical equipment damage due to large voltage and frequency variations, difficulties in phase shifting between the grid and the distributed generator when reconnecting after a fault, and risks to maintenance personnel and the general public. It is consequently critical to detect any islanding situations and lower the islanded system's operational time.

Three techniques have been proposed in this article. Their operation is based on the following characteristics: frequency, amplitude or phase of the voltage at the grid connection point of the decentralized generator. This study proposes an inventory of the different methods of islanding, and highlights their detection principles, advantages and disadvantages. To test the performance and reliability of these 
techniques, as well as to check the performance and efficiency of the effective method plan, simulation in the physical security information management (PSIM) environment was established.

\section{ACTIVEISLANDING DETECTION METHOD}

\subsection{Active frequency drift (AFD)}

With active frequency drift (AFD), the inverter current waveform is very slightly unstable, as shown in Figure 1, for a drift regime. AFD can be obtained by including a zero $t_{z}<833 \mu s$ (dead time of PV inverter current) bending segment. Or by forcing the frequency of the current to be higher than the frequency of the voltage of the previous cycle by a frequency offset $\delta f<1.5 \mathrm{~Hz}$. The value of the zero current segment $t_{z}$ or the frequency $\delta f$ is limited to the total harmonic distortion of the current $T H D_{i}<5 \%$. When there is a network, it will maintain the voltage frequency point of common coupling (PCC). However, when the photovoltaic system is disconnected from the grid [1], the voltage frequency at PCC tends to drift upwards, reaching a value higher than the resonance frequency $f_{0}$ the parallel resistor-inductor-capacitor (RLC) load [2]. This increases the risk that the net inductive load will trip the over freuency protection (OFP) at the nominal grid frequency. In both cases, the basic component of the current flows through a small angle $\theta_{\mathrm{AFD}}$ (Equivalent phase angle of current and voltage of inverter with AFD) before the voltage.

The waveform of the distorted current carries out the active frequency drift upwards, as shown in Figure 1. Displays the PCC voltage, the waveform of the inverter output current, and the basic components of the inverter current. The dominant equation is (1):

$$
i_{p v}=I \sin \left(2 \pi f_{i} t\right)=I \sin [2 \pi(f+\delta f)] t
$$

where $f=f_{v}$ is the frequency of the PCC voltage.

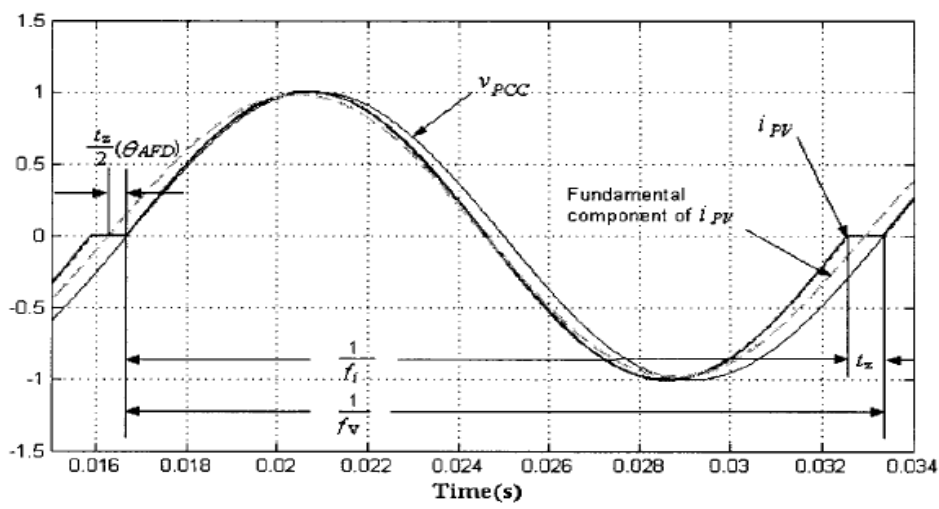

Figure 1. Current and voltage waveforms of upward AFD [2]

Figure 1 shows that although the output current of the photovoltaic (PV) inverter is in phase with the PCC voltage, the waveform of the current is neither odd nor even. In order to simplify the calculation of the phase angle between the basic components of voltage and current, the beginning of the basic current has been shifted by $-t_{z} / 2$. Therefore, the basic component of the output current of the $i_{p v}$ inverter drives the PCC voltage at an angle proportional to $-t_{z} / 2$ [3], [4]. The angle can be calculated in (2):

$$
\frac{\frac{\mathrm{t}_{\mathrm{z}}}{2}}{\mathrm{~T}_{\mathrm{v}}}=\frac{\theta_{\mathrm{AFD}}}{2 \pi}
$$

where $t_{z}=\frac{1}{f_{v}}-\frac{1}{f_{i}}=\frac{1}{f}-\frac{1}{f+\delta f}$ and is commonly called dead time $T_{v}$ is the time period of the voltage. Therefore, the phase angle between the fundamental current of the inverter and the PCC voltage is (3).

$$
\theta_{A F D}=\pi f t_{z}=\pi f\left(\frac{1}{f}-\frac{1}{f+\delta f}\right)=\frac{\pi \delta f}{f+\delta f}
$$

This phase angle plays an important role in mapping the non-detection zone (NDZ). AFD can achieve acceleration or penetration properties in theory. Their impact, however, is highly dependent on the sort of reactive stress. The load voltage, or PCC voltage, is specified by the grid voltage before disconnecting 
from the grid, and the inverter current is constrained to be in phase with the PCC voltage. The current will be distorted due to the predetermined acceleration. The load voltage will lose the reference voltage after being disconnected from the grid and will no longer be fixed by the grid. If the load is a pure resistance, the preset acceleration rate will raise the frequency of the inverter current in the next cycle, while also raising the frequency of the load voltage. The voltage waveform will lag behind the inverter current because the load is capacitive, and the effective acceleration will be smaller than the specified value. As a result, the generated acceleration increment is smaller than the preset value, and as the frequency increases, it gets smaller and smaller. They can reach 0 before the trip limit is reached, resulting in islanding. The effective frequency will increase for net inductive loads, which will assist speed up the process and improve islanding protection. Because most loads are inductive, AFD's preferred mode of operation is acceleration [5], [6].

\subsection{Slip mode phase shift (SMS)}

The difference between the frequency of the PCC voltage in the previous cycle and the grid's nominal operating frequency drives the change in current phase angle in the slip mode phase shift (SMS) approach. When the frequency increases, phase advance happens, and when the frequency decreases, phase delay occurs [7], [8].

The refernce of the inverter current is (4):

$$
i_{p v}=\operatorname{Isin}\left(2 \pi f t+\theta_{S M S}\right)
$$

with, $\theta_{S M S}$ : With SMS, the current and voltage phase angles of the inverter are equivalent. Set the phase shift as a sinusoidal function of the frequency deviation from the mains frequency fg, then:

$$
\theta_{S M S}=\frac{2 \pi}{360} \theta_{m} \sin \left(\frac{\pi}{2}-\frac{f-f_{g}}{f_{m}-f_{g}}\right)
$$

with, $\theta_{m}$ :Maximum phase shift $\operatorname{SMS}\left({ }^{\circ}\right)$. Where $f_{m}$ is the frequency at which the maximum phase shift $f_{m}$ occurs, and $f_{m}$ is the maximum phase shift in degrees $\left(^{\circ}\right)$. Like AFD, this phase angle plays an important role in NDZ mapping.

After connecting the utility program, it will provide the solid phase and frequency, which are considered as the constant voltage waveform reference of the PCC. However, for an island system, the frequency at the PCC will vary according to the current injected by the inverter and will reach a steady state value, which can be calculated according to the load and SMS characteristics of the inverter. The steady-state frequency can be calculated as the frequency at which the inverter angle and the load have the same value. Frequency can also be identified by graphs [9], [10]. the relationship curve between the load angle $\theta_{\text {load }}$ and frequency intersects the curve between the SMS angle $\theta_{S M S}$ and frequency according to the formula. Figure 2 shows the frequency response SMS and the load phase response as a function of frequency. This figure shows the phase response of two loads with the same resonant frequency, where $f_{0}=60 \mathrm{~Hz}$ and the quality factors are $Q_{f}=5$ and $Q_{f}=1.5$. The intersection of the SMS group and the load phase response is indicated by points $\mathrm{A}, \mathrm{B}$, and $\mathrm{C}[11],[12]$.

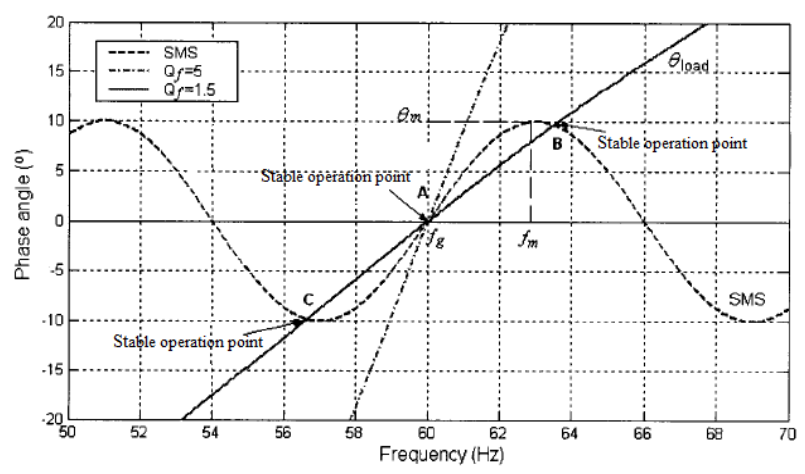

Figure 2. SMS phase response cuvre and parallel RLC load phase response cuvre [12]

However, the intersection of the load line and the phase response box of the inverter may be a stable or unstable operating point. The unstable operating point of $\frac{d \theta_{S M S}}{d f}>\frac{d \theta_{\text {load }}}{d f}$ is at the point A where the load quality factor is $Q_{f}=1.5$, and the stable operating point of is at the point A where the load quality factor is 
$Q_{f}=5$. Points B and C are stable with respect to the load $Q_{f}=1.5$. The stable operating point indicates the steady state frequency of the island system. The SMS parameters must be selected in such a way that there is no stable operating point within the permissible range of the mains frequency between the settings of the under frequency protection (UFP) and OFP devices.

\subsection{Sandia frequency shift (SFS)}

The current approach of islanding detection is a continuation of the frequency bias method, also known as active frequency drift with positive feedback. Positive feedback is used in the Sandia frequency shift (SFS) approach. This feedback will be applied to the voltage frequency of the interconnection point, and will try to generate interference on the grid by changing the frequency of the inverter output current to detect islanding more quickly. In order to set the inverter frequency to a different strategy than the grid frequency, as shown in Figure 3, the inverter output current shape is smoothly added or switched off [11], [12].

Figure 3, shows the example of the PV system inverter with an undistorted sine waveform for comparison. During the first half of the cycle, the output current of the PV system is a sinusoidal waveform whose frequency is higher than the frequency of the PCC voltage. When the output current of the PV inverter reaches zero, it remains at zero for the time $t_{z}$ before the start of the second half of the cycle. The higher frequency also applies to the second half of the current cycle. The dead time of the second cycles is not set by the PV inverter [13], [14].

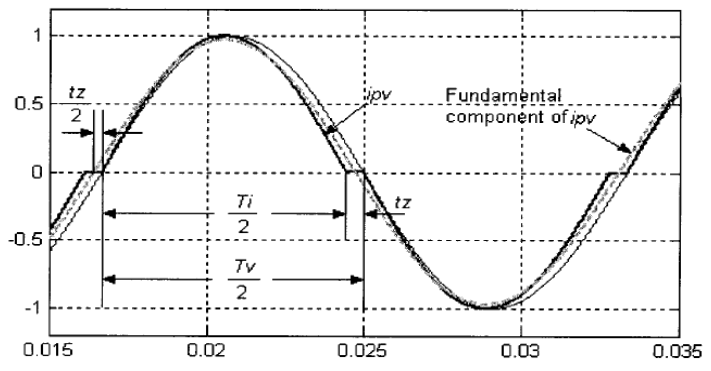

Figure 3. Waveforms with the SFS method [11]

A positive reaction is used to increase cutting factor $c_{f}$, which is mathematically defined as the ratio between time zero $t_{z}$ and half of the period of the PCC voltage waveform $\frac{T_{v}}{2}$. Therefore,

$$
c_{f}=\frac{2 t_{z}}{T_{v}}
$$

with an increasing deviation of the frequency from the nominal value. The erroris generally selected to be a linear function of the frequency of the increasingthe PCC voltage.

$$
c_{f}=c_{f 0}+F(\Delta f)=c_{f 0}+k_{s f s}\left(f-f_{g}\right)
$$

Where $c_{f 0}$ is a chopping factor when there is no frequency error, and $k_{s f s}$ is an accelerated gain [15], [16]. The SFS waveform has neither odd nor even symmetry, consequently, there will be a phase shift of the fundamental component of this form, wave equal to $0.5 \omega t$. If the zero current segments are small, the componentsharmonics of the current are also small, the SFS current can beapproximated by its set of out-ofphase fundamental components. Thus, the angle of the fundamental component of the inverter current varies with the frequency of the PCC, and the cutting factor cf [17], [18].

$$
\theta_{S F S}(f)=\frac{\omega t_{z}}{2}=\pi f t=\frac{\pi c_{f}(f)}{2}
$$

In order to remain in phase with the network voltage, at each zero crossing of the voltage of the grid the waveform of the inverter current is reset [19], [20]. Therefore, when the frequency of the current is higher than the mains frequency, the waveformof the current will complete its half cycle before the mains voltage drops to zero. Therefore, the current waveform will remain at zero until the next zero crossing ofthe mains voltage, then it will start a new sine half cycle [21]. Byelsewhere, if the frequency of the current is lower than that of the mains voltage, the passage at zero voltage will precede the end of the current half-cycle. Thus, this will resetthe current and will start a new sinusoidal cycle [22], [23]. 
Therefore, this will produce acut-off in the waveform of the inverter output current. As shown in Figure 4. Currently, this method appears to be one of the most proactive methods ofeffective in preventing islanding. In fact, it has one of the weakest NDAs. Frommore, when several inverters are connected in parallel to the same node, it is easyto be installed, inexpensive and always effective [24]. On the other hand, if the system is connected toa weak grid where the source of distributed generation is of some importance, thismethod will result in a slight decrease in the quality of the waveform of the current fromoutput of the inverter and can cause undesirable energy instability. The network's main one [25]. Therefore, this method remains a good compromise between the quality of the waveform, the efficiency of islanding detection and the effect on the transient response of the system. However when the local load connected to the point of interconnection has a factor ofhigher quality, the effectiveness of this method will be considerably reduced [26].

\section{SIMULATION RESULTS AND DISCUSSION}

A simulation was carried out for different detection methods with different loads in order to verify the theoretical analysis for the NDZ. It should be noted that if islanding is to occur, the voltage of the PCC must remain within the voltage limits when the network is disconnected. Thus, the amplitude of the reference current of the PV inverter is defined by $i_{\text {pvmax }}=\sqrt{2} V_{g} / R$ for the simulation. AFD performance is implemented for the case of frequency drift $\delta f=1 \mathrm{~Hz}$, and SMS is implemented for the case of $\theta_{m}=10^{\circ}$, $f_{m}=f_{g}=3 \mathrm{~Hz}$ and SFS is implemented for $f_{f 0}=0.05, k_{s f s}=0.05$.

\subsection{Simulation result of the AFD method}

Figure 4, shows the time response of the system with the AFD method, the PCC voltage, the current $i_{p v}$, the fault signal and the frequency $f_{P C C}$, when the circuit breaker of the network is open and the local load is $\mathrm{R}=14.4, \mathrm{C}=460.52 \mu \mathrm{F}$, and $\mathrm{L}=15.28 \mathrm{mH}$, which gives the resonance frequency $f_{0}=60 \mathrm{~Hz}$ and the quality factor $Q_{f}=2.5$. The mains circuit breaker is open, i.e. the mains is disconnected at $\mathrm{t}=0.07083 \mathrm{~s}$. From the voltage waveform it can be seen that with the preset reference value of the current $i_{\text {pvmax }}=$ $\sqrt{2} V_{g} / R=11.79 \mathrm{~A}$, the voltage amplitude has not had any apparent change before and after the mains disconnection. However, the frequency of the voltage $f_{P C C}$ has increased and exceeded the upper limit of the second cycle frequency after disconnection from the grid. It should be mentioned that the indicates the frequency of the last voltage cycle. The PV inverter stopped feeding the local load within six cycles after the frequency exceeded the upper limits of $\mathrm{t}=0.1822 \mathrm{~A}$ by switching off the inverter switches. It can be seen that the current $i_{p v}$ and the voltage $V_{P C C}$ all dropped to zero after the fault signal was changed to 1 . Thus, a load with f0 $=60 \mathrm{~Hz}$ and $Q_{f}=2.5$ is outside of the AFD NDZ during $\delta f=1 \mathrm{~Hz}$, which makes it possible to check the theoretical result.

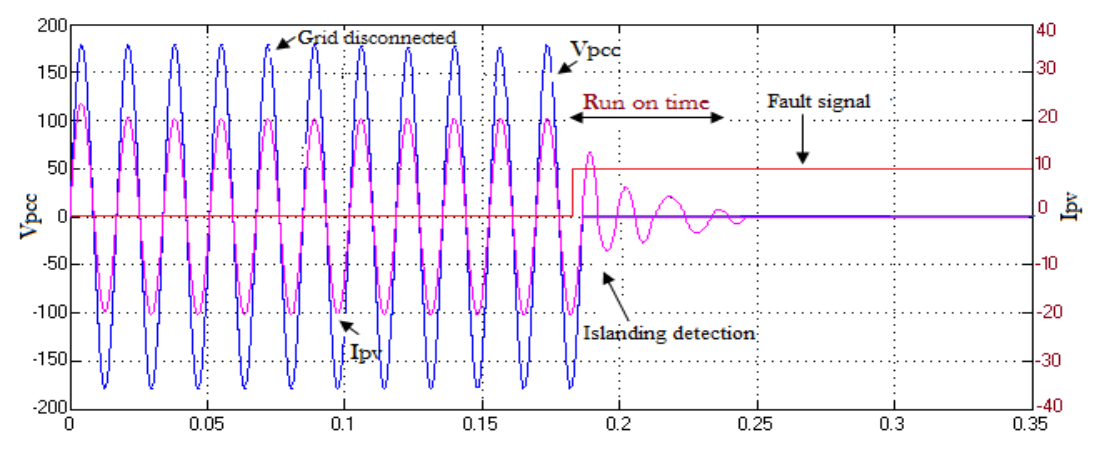

Figure 4. Simulation result of AFD supplying a local load $P_{\text {load }}=1 \mathrm{~kW}$, with $f_{0}=60 \mathrm{~Hz}$ and $Q_{f}=2.5$

In order to verify that the ZDN covers all the different resistance values, another simulation is performed with the load $\mathrm{R}=28.8, \mathrm{C}=187.33 \mu \mathrm{F}$, and $\mathrm{L}=38.85 \mathrm{mH}$, which gives the resonance frequency $f_{0}=59 \mathrm{~Hz}$ and the quality factor $Q_{f}=2$. Figure 5 shows the time response of the system, the PCC voltage, the current $i_{p v}$, the fault signal and the frequency $f_{P C C}$. The mains circuit breaker is open, i.e. the mains is disconnected, at $\mathrm{t}=0.07083 \mathrm{~s}$. The amplitude of the reference current is set to $I_{P V m x}=5.89$ A to maintain the amplitude of the PCC voltage. The frequency of the voltage $f_{P C C}$ has decreased to a steady state value within the frequency protection threshold. The fault signal remains at 0 . The undetectable islanding operation has occurred, and the inverter is continuously feeding the load, resulting in the PV current $i_{p v}$ and the $V_{P C C}$ 
voltage. Thus, a load with $f_{0}=59 \mathrm{~Hz}$ and $Q_{f}=2$ is in the AFD NDZ for $\mathrm{f}=1 \mathrm{~Hz}$ as predicted by the theoretical analysis.

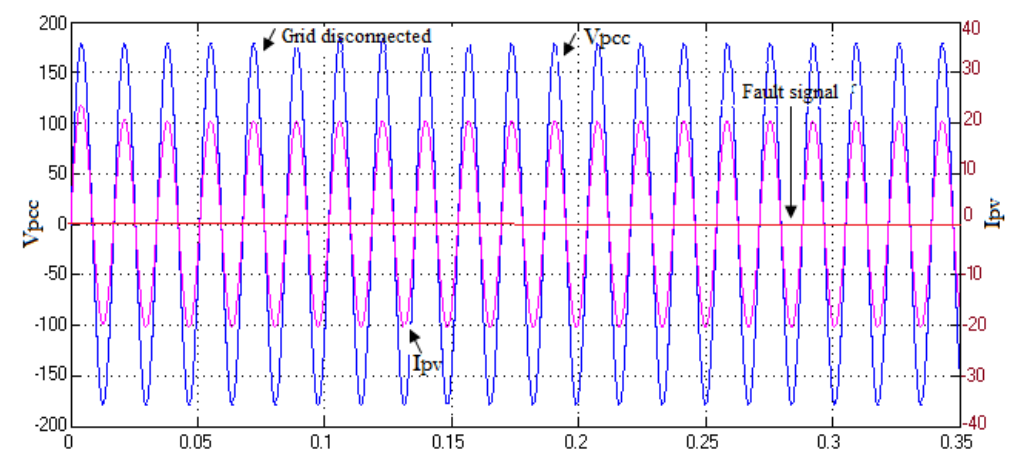

Figure 5. Simulation result of AFD supplying a local load $P_{\text {load }}=0.5 \mathrm{~kW}$, with $f_{0}=60 \mathrm{~Hz}$ and $Q_{f}=2$

\subsection{Simulation result of the SMS method}

Similar tests were performed for the grid-connected inverter using SMS with $\theta_{m}=10^{\circ}$ and $f_{m}=f_{g}=3 \mathrm{~Hz}$. Figure 6, shows the system response in the time domain with SMS, PCC voltage, current $i_{P V}$, fault signal and frequency $f_{P C C}$, when the grid breaker opens and the local load is $\mathrm{R}=14.4$, $\mathrm{C}=460.52 \mu \mathrm{F}$ and $\mathrm{L}=15.28 \mathrm{mH}$, which gives the resonance frequency $f_{0}=60 \mathrm{~Hz}$ and the quality factor $Q_{f}=2.5$. The mains circuit breaker is open, i.e. the mains is disconnected, at $\mathrm{t}=0.07083 \mathrm{~s}$, the positive peak of the fifth cycle of the PCC voltage. The frequency of the voltage $f_{P C C}$ has decreased and has become lower than the setpoint UFP after disconnection from the grid. The PV inverter stopped feeding the local load within 6 cycles after the frequency exceeded the lower frequency limits at $t=0.4027 \mathrm{~s}$ by turning off the inverter switches. It can be seen that the PV current and the $V_{P C C}$ voltage all dropped to zero after the fault signal changed to 1 . Thus, a load with $f_{0}=60 \mathrm{~Hz}$ and $Q_{f}=2.5$ is outside the NDZ SMS for $\theta_{m}=10^{\circ}$, so the results of the calculation can be checked.

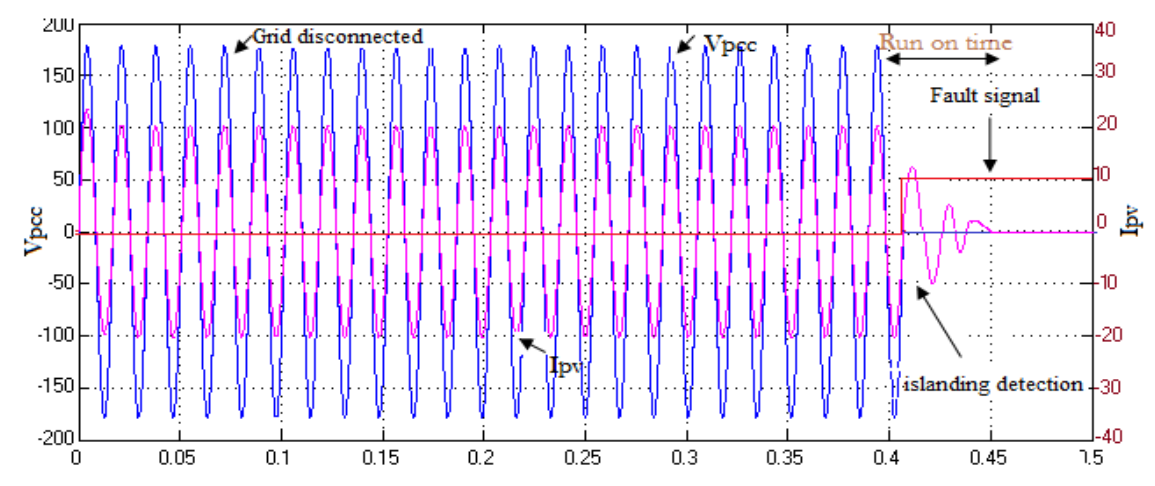

Figure 6. Simulation result of SMS supplying a local load $P_{\text {load }}=1 \mathrm{~kW}$, with $f_{0}=60 \mathrm{~Hz}$ and $Q_{f}=2.5$

Another simulation is performed with the load, $\mathrm{C}=552.62 \mu \mathrm{F}$ and $\mathrm{L}=12.73 \mathrm{mH}$, which gives the resonance frequency $f_{0}=60 \mathrm{~Hz}$ and the quality factor $Q_{f}=3$. Figure 7 shows the time domain response of the PCC system voltage, $i_{P V}$ current, fault signal and frequency $f_{P C C}$. The mains circuit breaker is open, i.e. the mains is disconnected at $\mathrm{t}=0.07083$. After disconnection from the grid, the frequency of the $f_{P C C}$ voltage has decreased, but has reached the steady state within the frequency protection threshold. The fault signal remains at 0 . The undetectable islanding operation has occurred, and the inverter is continuously feeding the load, as shown by the current $i_{P V}$ and the VPCC voltage. Thus, a load with $f_{0}=60 \mathrm{~Hz}$ and $Q_{f}=3$ and is within the NZD range of the SMS for $\theta_{m}=10^{\circ}$ as predicted by the theoretical analysis. 


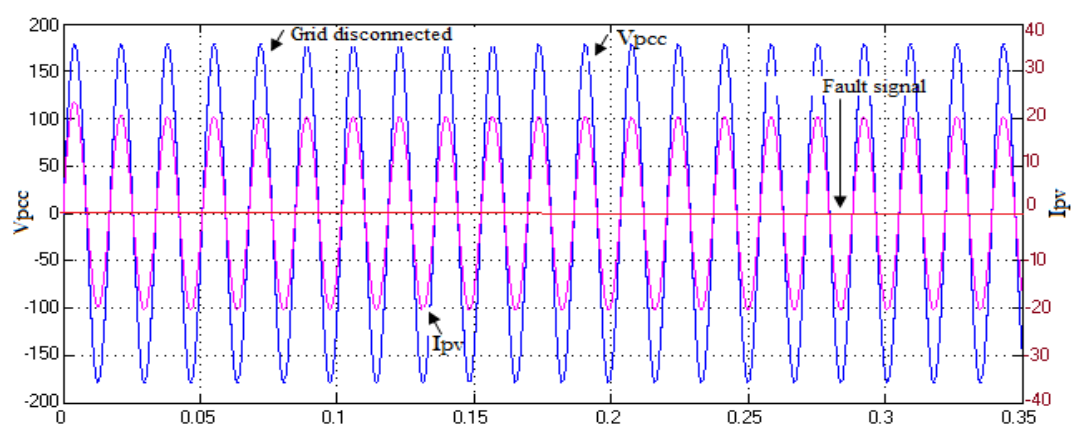

Figure 7. Simulation result of SMS supplying a local load $P_{\text {load }}=1 \mathrm{~kW}$, with $f_{0}=60 \mathrm{~Hz}$ and $Q_{f}=3$

\subsection{Simulation result of the SFS method}

Similar tests were performed for the grid-connected inverter using FSS with $c_{f 0}=0.05$, $k_{S F S}=0.05$, Figure 8 , shows the time domain response of the system with FSS, PCC voltage, $i_{P V}$ current, fault signal and frequency $f_{P C C}$. When the grid breaker opens and the local load is $\mathrm{R}=14.4, \mathrm{C}=460.52 \mu \mathrm{F}$ and $\mathrm{L}=15.28 \mathrm{mH}$, which gives the resonance frequency $f_{0}=60 \mathrm{~Hz}$ and the quality factor $Q_{f}=2.5$. The circuit breaker of the open network, i.e. the network is disconnected, at $t=0.07083 \mathrm{~s}$, the positive peak of the fifth cycles of the $V_{P C C}$ voltage. The frequency $f_{P C C}$ of the voltage has increased and exceeded the lower limit of the frequency after disconnection from the grid. The PV inverter stopped feeding the local load within 6 cycles after disconnection from the grid. The frequency exceeded the upper frequency limit at $\mathrm{t}=0.1626 \mathrm{~s}$ by switching off the inverter switches. It can be seen that the PV current $i_{P V}$ and the $V_{P C C}$ voltage all decreased from zero after the fault signal changed to 1 . Thus, a load with $f_{0}=60 \mathrm{~Hz}$ and $Q_{f}=2.5$ is outside the FSS NDZ area for $c_{f 0}=0.05$ and $k_{S F S}=0.05$, which allows checking the results of the calculation.

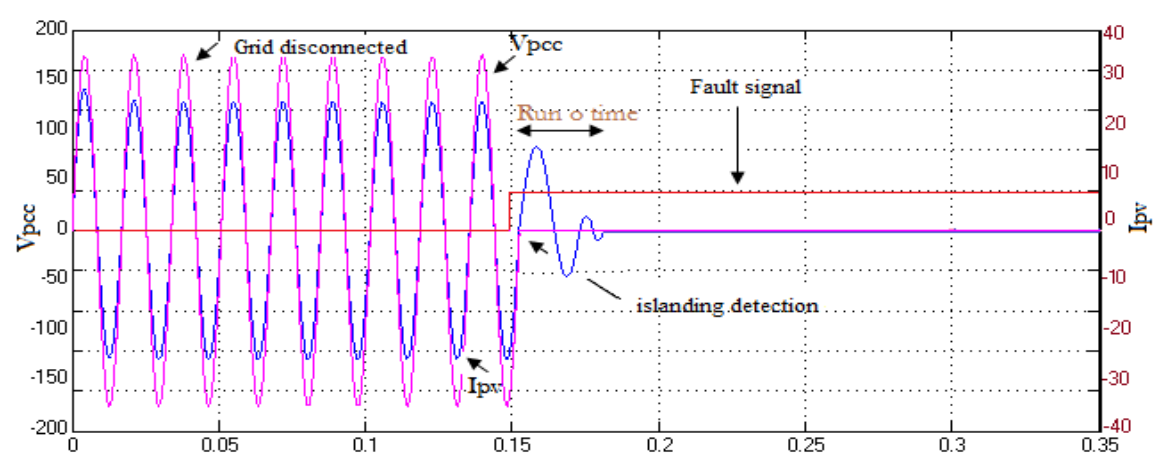

Figure 8. Simulation result of SFS supplying a local load $P_{\text {load }}=1 \mathrm{~kW}$, with $f_{0}=60 \mathrm{~Hz}$, and $Q_{f}=2.5$

Another simulation is performed with the load, $\mathrm{C}=561.04 \mu \mathrm{F}$ and $\mathrm{L}=12.93 \mathrm{mH}$, which gives the resonance frequency $f_{0}=59.1 \mathrm{~Hz}$ and the quality factor $Q_{f}=3$. The time domain response of the PCC system voltage, $i_{P V}$ current, fault signal and frequency $f_{P C C}$ is shown in Figure 9. The mains circuit breaker is open, i.e. the mains is disconnected at $t=0.07083 \mathrm{~s}$. The frequency of the voltage $\mathrm{f}$ PCC has reduced after being disconnected from the grid, but it had now stabilized within the frequency protection level. The fault signal is still at zero. The undetectable islanding operation has occurred, and the inverter is continuously feeding the load, as shown by the current $i_{P V}$ and the $V_{P C C}$ voltage. Thus, a load with $f_{0}=59.1 \mathrm{~Hz}$ and $Q_{f}=3$ is in the NDZ zone of the SMS for $c_{f 0}=0.05$ and $k_{S F S}=0.05$ as predicted by the theoretical analysis.

One technique was picked after an investigation of the best islanding detection methods. The method chosen is actually a combination of a passive method and two active methods. The option of a combination of methods was kept since decreasing the NDZ improves the performance of the islanding detecting system. 


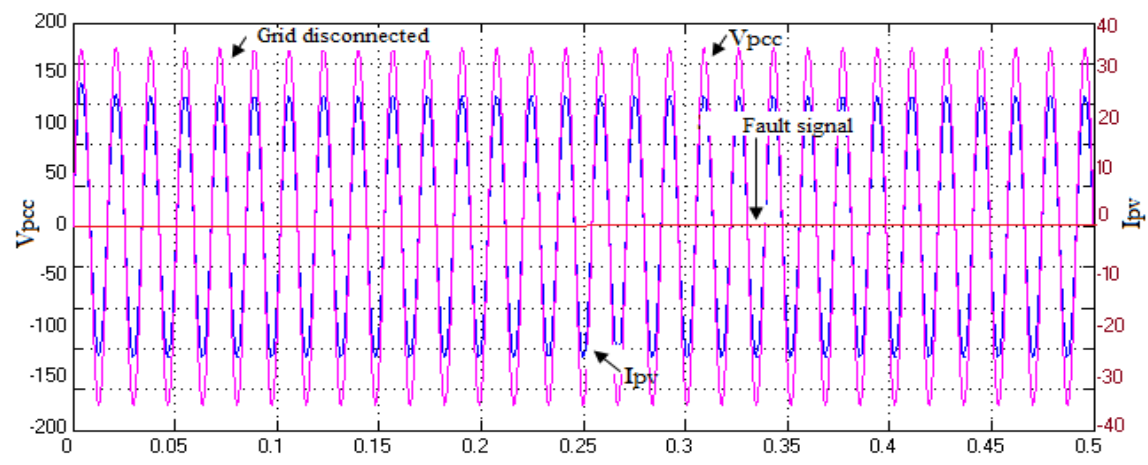

Figure 9. Simulation result of SFS supplying a local load $P_{\text {load }}=1 \mathrm{~kW}$, with $f_{0}=59.1 \mathrm{~Hz}$ and $Q_{f}=3$

The system's basic protection will be provided via the under/over voltage and under/over frequency methods. Because the frequency or amplitude of the voltage at the point of connecting exceeds the prescribed limitations, the inverter stops sending electricity to the grid. The root mean square (RMS) value of the voltage amplitude at the point of interconnection must be between $88 \%$ and $110 \%$ of the nominal grid voltage, and the frequency must be between $59.5 \mathrm{~Hz}$ and $60.5 \mathrm{~Hz}$, according to the European standard.

The active SFS approach was chosen as the second method. This strategy was chosen because it appears to be one of the most effective active strategies for avoiding islanding scenarios currently available. It does, after all, have one of the lowest NDZs. When many inverters are paralleled on a single connection node, it is also simple to construct, economical, and effective.

\section{CONCLUSION}

According to their placement in distributed generation systems, these approaches can be split into two categories: local and remote procedures. The distant sensing technique is used on the main grid side, whereas the sensing algorithm is used in the inverter for local techniques. Furthermore, local approaches are divided into two categories: i) passive methods, which rely on parameter estimation such as voltage, current, and harmonics, and ii) active methods, which use disturbances to detect islanding. Simulation was used to validate the theoretical analysis and the equation characterizing the NDZ of three common active integrated database management systems (IDMs). Matlab/Simulink was used to model and simulate the grid-connected PV system. The hysteresis control blocks, frequency and RMS, and the reference current with IDM are all model components. To verify the theoretical study, simulations of various IDMs, including AFD, SMS, and FSS, were run with various resonant frequencies and quality factor loads. These three IDMs' NDZ simulation results were plotted to compare with the theoretical results. The comparison of the various simulation results demonstrates the efficiency of the SFS method over the other methods. Because it has one of the lowest NDZs, this technique was chosen.

\section{ACKNOWLEDGEMENTS}

The authors are grateful for the financial assistance of the research project on $6 \mathrm{kVA}$ inverters from the Institute of Research in Solar Energy and New Energies (IRESEN).

\section{REFERENCES}

[1] V. Singh, "Islanding Detection Using Improved SMS Method In Grid Connected Converters," Malaviya National Institute of Technology, 2016.

[2] H. Sun, "Performance assessment of islanding detection methods using the concept of non-detection zones," Concordia University, 2005.

[3] M. Ciobotaru, "Reliable grid condition detection and control of single-phase distributed power generation systems," Aalborg Universitet, 2009.

[4] A. C. Gonzalez, "Système de contrôle pour l'intégration des sources d'énergie décentralisées au réseau local," Université du Québec à Trois-Rivières, 2012.

[5] M. Robitaille, "Élaboration d'une méthode de protection d'îlotage pour un système de production distribuée connecté à un réseau électrique local,” Université du Québec à Trois-Rivières, 2006.

[6] Y. Xue, L. Chang, S. B. Kjaer, J. Bordonau, and T. Shimizu, "Topologies of Single-Phase Inverters for Small Distributed Power Generators: An Overview," IEEE Transactions on Power Electronics, vol. 19, no. 5, pp. 1305-1314, Sep. 2004, doi: 10.1109/TPEL.2004.833460.

[7] J. Merino, P. Mendoza-Araya, G. Venkataramanan, and M. Baysal, "Islanding Detection in Microgrids Using Harmonic Signatures," IEEE Trans. Power Delivery, vol. 30, no. 5, pp. 2102-2109, Oct. 2015, doi: 10.1109/TPWRD.2014.2383412. 
[8] B. Yu, Abo-Khalil, and A. Galal, "Optimized AFD anti-islanding method for grid connected PV system," International Conference on Convergence Technology, vol. 2, no. 1, pp. 1783-1784, 2013.

[9] E. O. Schweitzer, D. Whitehead, G. Zweigle, and K. G. Ravikumar, "Synchrophasor-based power system protection and control applications," in 2010 63rd Annual Conference for Protective Relay Engineers, Mar. 2010, pp. 1-10, doi: 10.1109/CPRE.2010.5469481.

[10] E. Kamyab and J. Sadeh, "Islanding detection method for photovoltaic distributed generation based on voltage drifting," IET Generation, Transmission \& Distribution, vol. 7, no. 6, pp. 584-592, Jun. 2013, doi: 10.1049/iet-gtd.2012.0507.

[11] Gwon-jong Yu et al., "Boundary conditions of reactive-power-variation method and active-frequency-drift method for islanding detection of grid-connected photovoltaic inverters," in Conference Record of the Thirty-first IEEE Photovoltaic Specialists Conference, 2005., pp. 1785-1787, doi: 10.1109/PVSC.2005.1488497.

[12] K. G. M., A synchronization scheme based on an enhanced phase-locked loop system. 2004.

[13] I. Pvps, "Evaluation of islanding detection methods for photovoltaic utility-interactive power systems," 2002.

[14] T. Funabashi, K. Koyanagi, and R. Yokoyama, "A review of islanding detection methods for distributed resources," in 2003 IEEE Bologna Power Tech Conference Proceedings, vol. 2, pp. 608-613, doi: 10.1109/PTC.2003.1304617.

[15] F. Noor, R. Arumugam, and M. Vaziri, "Unintentional islanding and comparison of prevention techniques," in Proceedings of the 37th Annual North American Power Symposium, 2005., pp. 90-96, doi: 10.1109/NAPS.2005.1560507.

[16] W. BOWER and M. ROPP, "Evaluation of Islanding Detection Methods for Utility-Interactive Inverters in Photovoltaic Systems," Albuquerque, NM, and Livermore, CA (United States), Nov. 2002. doi: 10.2172/806700.

[17] R. S. Kunte and W. Gao, "Comparison and review of islanding detection techniques for distributed energy resources," in 2008 40th North American Power Symposium, Sep. 2008, pp. 1-8, doi: 10.1109/NAPS.2008.5307381.

[18] L. A. C. Lopes and H. Sun, "Performance Assessment of Active Frequency Drifting Islanding Detection Methods," IEEE Transactions on Energy Conversion, vol. 21, no. 1, pp. 171-180, Mar. 2006, doi: 10.1109/TEC.2005.859981.

[19] F. Liu, Y. Kang, and S. Duan, "Analysis and optimization of active frequency drift islanding detection method," in APEC 07 Twenty-Second Annual IEEE Applied Power Elec. Conf. Exposition, 2007, pp. 1379-1384, doi: 10.1109/APEX.2007.357696.

[20] Y. Jung, J. Choi, and G. Yu, “A Novel Active Anti-islanding Method for Grid-connected Photovoltaic Inverter," Journal of Power Electronics, vol. 7, no. 1, pp. 64-71, 2007.

[21] Z. Ye, A. Kolwalkar, Y. Zhang, P. Du, and R. Walling, "Evaluation of Anti-Islanding Schemes Based on Nondetection Zone Concept," IEEE Transactions on Power Electronics, vol. 19, no. 5, pp. 1171-1176, Sep. 2004, doi: 10.1109/TPEL.2004.833436.

[22] M. Robitaille, K. Agbossou, and M. L. Doumbi, "Modeling of an islanding protection method for a hybrid renewable distributed generator," in Canadian Conf. Electrical and Computer Engineering, 2005., pp. 1485-1489, doi: 10.1109/CCECE.2005.1557259.

[23] A. F. Sapar, C. K. Gan, M. Shamshiri, and A. N. Ramani, "Performance Assessment of Slip Mode Frequency Shift (SMS) Islanding Detection Methods," Applied Mechanics and Materials, vol. 699, pp. 546-551, Nov. 2014, doi: 10.4028/www.scientific.net/AMM.699.546.

[24] Huili Sun, L. A. C. Lopes, and Zhixiang Luo, "Analysis and comparison of islanding detection methods using a new load parameter space," in 30th Annual Conference of IEEE Industrial Electronics Society, 2004. IECON 2004, vol. 2, pp. 1172-1177, doi: 10.1109/IECON.2004.1431741

[25] F. Liu, Y. Kang, Y. Zhang, S. Duan, and X. Lin, "Improved SMS islanding detection method for grid-connected converters," IET Renewable Power Generation, vol. 4, no. 1, pp. 36-42, 2010, doi: 10.1049/iet-rpg.2009.0019.

[26] N. Ikken, N-E. Tariba, A. Bouknadel, A. Haddou, H. E. Omari, and H. E. Omari, "A fuzzy rule based approach for islanding detection in grid connected inverter systems," vol. 11, no. 6, pp. 4759-4766, 2021, doi: 10.11591/ijece.v11i6.pp4759-4766.

\section{BIOGRAPHIES OF AUTHORS}

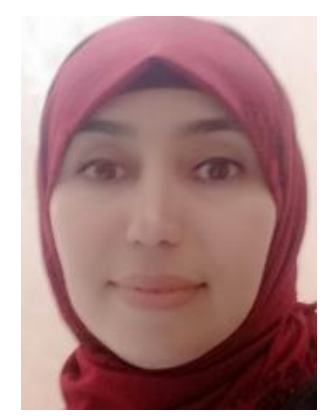

Naima Ikken (D) 8f SC P was born in Oulmes in the Middle Atlas in Morocco. She graduated in renewable energy and system energy from HASSAN II University-Casablanca in 2013. Currently she is a Ph.D. candidate in Physics and Engineering Science at the renewable Energy, Environment and Development Laboratory (ERED) of Hassan I University, Faculty of Science and Technology (FST), Settat-Morocco. She can be contacted at email: naima.ikken@gmail.com.

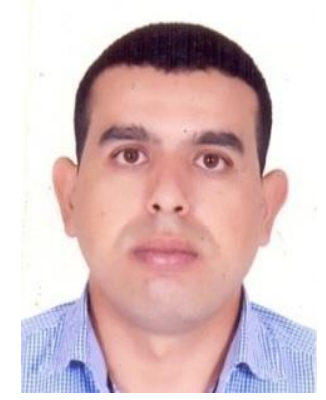

Nour-Eddine Tariba (D) SC P was born in Taza, Morocco, in November 1985. He received his master's degree in Microelectronics from the IBN TOUFAIL University in Kénitra, Morocco. Currently, he works at Lear Corporation as a high-power electronics hardware engineer. His current research interests include electronic design and control for high power electronics systems. $\mathrm{He}$ can be contacted at email: noureddinetariba@gmail.com. 

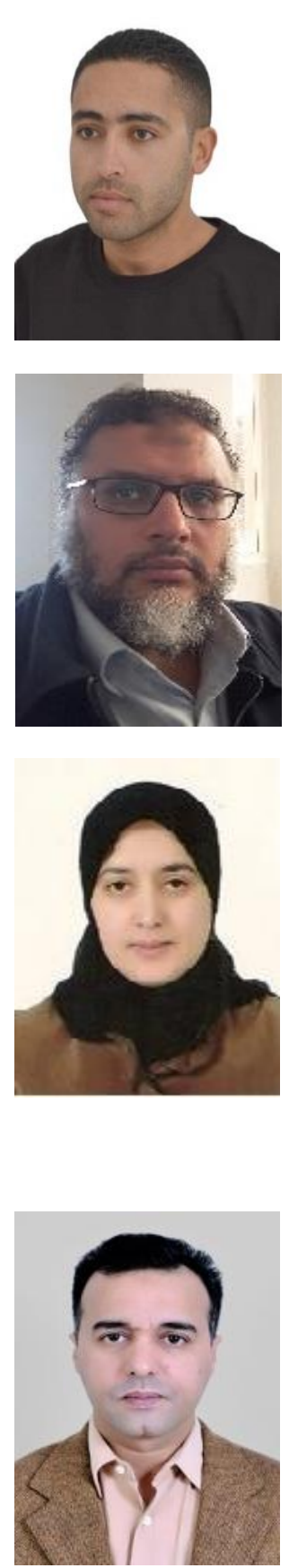

Abdelhadi Bouknadel (iD ) gl SC P was born in El Jadida, Morocco, on February 26, 1989. He graduated in electromechanical from ENSAM "National school of arts and crafts Meknes" in Morocco. After graduation, he worked as a full time employee with the Adeneo Group at ADETEL MAROC affiliate. His work at Adeneo has included electronic design, power electronic design and simulation, and system design. He can be contacted at email: abdelhadi.bouknadel@gmail.com.

Ahmed Haddou (iD 81 SC P Haddouwas born in Khouribga, Morocco.onJune01, 1974. He graduated in electronic from Institute of Electronics, Microelectronics and Nanotechnology of The University of Valenciennes and Hainaut Cambrésis in France. For 20 years, Ahmed Haddouhave contributed to the development of hardware embedded systems programs in the automotive and aerospace industry in France and Morocco (VALEO, Hispano suiza, EADS, ADETEL MAROC, NSS MAROC). He can be contacted at email: Haddou@gmail.com.

Hafsa El Omari (D) SI SC P was born on April 15, 1974 in Oulmès in the Middle Atlas in Morocco. She prepared her Advanced Studies Diploma (DEA) in microelectronics and a $\mathrm{PhD}$ Doctorate Degree in electrical engineering from INSA Lyon in France. Her doctoral thesis, carried out at the CEGELY laboratory, electrical engineering center at INSA Lyon, focused on the modeling and simulation of power components such as VDMOS, IGBT transistors, etc. She then spent two years as Temporary Teaching and Research Assistant (ATER) in the LAM automatic and electronics laboratory at the Champagne Ardenne University in Reims in France. In parallel to this training, she followed a Masters in IT management at INSA Lyon, and prepared other certificates in IT development at the Qualea center in Bron in France. Since 2007, she has been recruited to a teaching and research position at Hassan I University in Settat (ENCG-Settat). She is a permanent member of the laboratory for renewable energies, environment and development (LERED) at the FST in Settat. She can be contacted at email: haf.elo@gmail.com.

Hamid El Omari (iD 8I SC P was born on 12/09/1966 in Oulmès in the Middle Atlas in Morocco. Since November 1994, he obtained his PhD at the National Institute of Applied Sciences (INSA) of Lyon-Laboratory of Physics of Matter (in France). In 1998, He prepared the accreditation to supervise research (HDR) at INSA of Lyon in France. Its previous research activities have improved the quality ratio of multicrystalline silicon solar cells through the use of a new Anti-Reflective Coating deposition procedure (ARC before Screen Printing Contact deposition) that favours the reduction of the silicon reflection coefficient as well as the formation of good quality ohmic contacts. His work has also led to the implementation of a new method TLM (Transmission Line Model) for measuring contacts on multi-crystalline substrates (multicrystalline, polycrystalline, amorphous, or porous). In 2006, Professor Hamid EL OMARI created the first Renewable Energy Laboratory in Morocco at Hassan Premier University. The various research activities under the supervision of Professor Hamid EL OMARI concern either green energy conversion systems (inverter; speed variator; simulations, study, and metrology of photovoltaic stations; and solar cars) or the storage in some forms of green energy (solar water heater; biodigester or biogas with cogeneration). All projects supervised by Professor Hamid EL OMARI are funded by the Research Institute of Solar Energy and New Energies (IRESEN) under the Ministry of Energy, Mining \& Sustainable Development in Morocco (whose inverter is the subject of this article), and the National Center for Scientific and Technical Research (CNRST) under the Ministry of Higher Education, Scientific Research and Executive Training of Morocco. He can be contacted at email: elomari.hamid@gmail.com. 